\title{
CARDIOMETABOLIC RISK FACTORS ASSOCIATED WITH RENAL FUNCTION IN APPARENTLY HEALTHY YOUNG STUDENTS: A CROSS-SECTIONAL STUDY
}

\author{
lucia M. Pérez-Navarro ${ }^{1}$, Rafael Valdez-Ortiz ${ }^{1}$, Araceli Alegría-Díaz ${ }^{1}$, Miguel Murguía-Romero ${ }^{2,3}$, \\ Rafael JimÉnez-Flores ${ }^{2,3}$, Rafael Villalobos-Molina ${ }^{2,3}$, Srinivas Mummidi ${ }^{4}$, RaVindranath DugGiRala ${ }^{4}$, \\ AND JUAN C. LóPEZ-Alvarenga ${ }^{4,5}$ \\ ${ }^{1}$ Department of Nephrology, Hospital General de México “Dr. Eduardo Liceaga," Mexico City, Mexico; \\ ${ }^{2}$ Iztacala School of Graduate Studies, National Autonomous University of Mexico (FES-I.-UNAM), Tlalnepantla, Edo. \\ Mex., Mexico; ${ }^{3}$ National Laboratory in Health, Molecular Diagnosis and Environmental Effect in Chronic-Degenerative \\ Diseases, UNAM, Tlalnepantla, Edo. Mex., Mexico; ${ }^{4}$ South Texas Diabetes and Obesity Institute and Department \\ of Human Genetics, School of Medicine, University of Texas Rio Grande Valley, Edinburg, Texas, USA; ${ }^{5}$ Universidad \\ México-Americana del Norte, Reynosa, Tamps., Mexico
}

\begin{abstract}
Background: Cardiometabolic risk factors (CMRFs) appear decades before developing chronic kidney disease (CKD) in adulthood. Objective: The objective of the study was to identify the prevalence and association between CMRFs and kidney function in apparently healthy young adults (18-25 years old). Methods: We included 5531 freshman year students. Data collected on CMRFs included central obesity, high body mass index (hBMl $>25$ ), blood pressure, glycemia, lipids, uric acid (UA >6.8 mg/dL), and insulin. Glomerular filtration rate (GFR) was estimated by CKD-Epidemiology Collaboration formula. We used logistic regression and a log linear for odds ratio (OR) (95\% confidence level) and probabilities. Results: The presence of any CMRF was observed in $78 \%$ (4312) of individuals; GFR $\geq 120 / 130 \mathrm{~mL} / \mathrm{min} / 1.73 \mathrm{~m}^{2} \mathrm{sc}$ was found in $33 \%, \mathrm{GFR}<90 \mathrm{~mL} / \mathrm{min} / 1.73 \mathrm{~m}{ }^{2} \mathrm{sc}$ in $3 \%$, and proteinuria in 3\%. Factors associated with high GFR were hBMI (OR 1.3 [1.14, 1.47]), UA (OR 0.2 [0.15, 0.26]), highdensity lipoprotein (HDL) (OR $1.4[1.2,1.6]$ ), and insulin resistance (OR $1.3[1.05,1.7])$. CMRF associated with low GFR was UA (OR $1.8[1.3,2.6]$ ), low-density lipoprotein cholesterol (OR $1.66[1.05,2.6]$ ), and proteinuria (OR 3.4 [2.07, 5.7]). Proteinuria was associated with high UA (OR 1.59 [1.01, 2.5]) and hypercholesterolemia (OR $1.8[1.03,3.18]$ ). The sole presence of $\mathrm{hBMI}+\mathrm{UA}$ predicted low GFR with $\mathrm{p}=0.6$ and $\mathrm{hBMI}+\mathrm{UA}+$ low HDL predicted proteinuria with $\mathrm{p}=0.55$. Conclusions: CMRFs were highly prevalent among this freshman student population and were associated with proteinuria and GFR abnormalities. Future studies should focus on public health programs to prevent or delay the development of CKD. (REV INVEST CLIN. 2020;72(2):95-102)
\end{abstract}

Key words: Cardiometabolic risk. Probability. Glomerular filtration rate. Healthy students. Kidney function tests.

*Corresponding author:

Juan C. López-Alvarenga

E-mail: juan.lopezalvarenga@utrgv.edu
Received for publication: 06-08-2019

Approved for publication: 25-11-2019

DOI: $10.24875 / R I C .19003204$

0034-8376 / (c) 2019 Revista de Investigación Clínica. Published by Permanyer. This is an open access article under the CC BY-NC-ND license (http://creativecommons.org/licenses/by-nc-nd/4.0/). 


\section{INTRODUCTION}

The incidence and prevalence of chronic kidney disease (CKD) has increased worldwide over the past two decades. In 2016, CKD was the $13^{\text {th }}$ leading cause of global death, whereas in Latin America, CKD ranked as the eighth leading cause of death ${ }^{1}$. The United States and Mexico have reported the highest incidence of treated CKD, with rates of 378 and 411 per million in the general population, respectively. In Mexico, the incidence of treated CKD increased by $63 \%$ and the CKD prevalence by $298 \%$ between 2002 and $2015^{2}$.

Individuals with CKD remain asymptomatic during the early stages and are often diagnosed during advanced stages that require substitution therapy. The annual cost per patient in Mexico is estimated at $\$ 12,500$ USD, and treating all CKD patients could impose an economic burden of up to $\$ 1650$ million USD per year ${ }^{3}$. Older adult population commonly reports a clinical history of cardiometabolic risk factors (CMRFs, i.e., type 2 diabetes [T2D], overweight, obesity, hypertension, and dyslipidemia) before CKD diagnosis. Notably, two or more of these factors can be detected even 30 years previous to CKD diagnosis.

In a meta-analysis, including 318,898 adults (ages 48-76 years), Tsai et al. ${ }^{4}$ found that the main risk factors for CKD were male sex (hazard ratio [HR] 1.37; $95 \%$ confidence level $[\mathrm{Cl}] 1.17,1.62)$, proteinuria $>1 \mathrm{~g} /$ day (HR $1.64 ; 95 \% \mathrm{Cl} 1.01,2.66$ ), and diabetes (any type) (HR 1.16; 95\% Cl: 0.98, 1.38). Thomas et al., in a meta-analysis, including 30,146 subjects, reported that metabolic syndrome (MetS) was associated with an estimated glomerular filtration rate (eGFR) of $<60 \mathrm{~mL} / \mathrm{min} / 1.73 \mathrm{~m}^{2}$ (odds ratio [OR] $1.55 ; 95 \% \mathrm{Cl} 1.34,1.8$ ), with a positive correlation to the number of individual metabolic components5. Finally, Hill et al., in another meta-analysis, including 6,908,440 subjects older than 35 years, reported that the prevalence of diabetes and hypertension was significantly associated with the prevalence of $C K D^{6}$.

We recently reported that adolescents and young adults in a cohort of $1^{\text {st }}$ year university students (Iztacala campus, UNAM) were also at increased risk of renal impairment and the quartiles of their serum uric acid (UA) concentrations had a positive correlation with $\mathrm{CMRFs}^{7}$. The Nephrology Department at the General Hospital of Mexico, in 2018, treated 16,587 CKD patients, of whom $7 \%$ were young (15-24 years old) and $24 \%$ were adults between 25 and 44 years of age ${ }^{8}$. McMahon et al. found that CKD patients have at least one unidentified risk factor for CKD since the age of 20. Unfortunately, young adults are not systematically screened for these risk factors, as they are presumed to be healthy. This is an alarming fact if we consider that in Mexico, $14.3 \%$ of the population is between 18 and 25 years old 9 .

To the best of our knowledge, no studies have been conducted in a young population to identify the CMRFs that best predict the progressive alteration in renal function, predisposing them to future CKD development. Therefore, the objective of this study was to identify the prevalence and strength of association between CMRFs and renal function in young adults 18-25 years of age.

\section{METHODS}

\section{Study design and variables}

This cross-sectional epidemiological study included 5531 students at the Iztacala School of Graduate Studies, National Autonomous University of Mexico (UNAM), Mexico City. Freshman students were invited to participate voluntarily between August 2008 and September 2015 for a brief physical examination and record their anthropometric measurements and resting blood pressure (BP). Blood was drawn for analysis of glucose, UA, lipids, and insulin after $8 \mathrm{~h}$ fasting. The following CMRF-related variables were measured (nominal scale): central obesity $(\mathrm{Ob}) \geq 90 / 80 \mathrm{~cm}$ for men (M)/women (W), overweight or obesity (high body mass index [hBMl] $>25$ or $>30$, respectively, according to the WHO classification); high BP (HBP; SBP, DBP, $\geq 130 / 85 \mathrm{mmHg}$ ), hyperglycemia ( $\geq 100 \mathrm{mg} / \mathrm{dL}$ ); hyperuricemia (UA > $6.8 \mathrm{mg} / \mathrm{dL}$ ); hypertriglyceridemia ( $\geq 150 \mathrm{mg} / \mathrm{dL}$ ), low high-density lipoprotein cholesterol (HDL-C $<50 / 40 \mathrm{mg} / \mathrm{dL} \mathrm{W} / \mathrm{M}$ ), high lowdensity lipoprotein cholesterol (LDL-C $>130 \mathrm{mg} / \mathrm{dL}$ ), and insulin resistance (IR; homeostatic model assessment [HOMA]-IR, > 2.3/2.9 W/M) ${ }^{10-12}$. MetS was defined according to the criteria established by the International Diabetes Federation and the American Heart Association/National Heart, Lung, and Blood 
Institute ${ }^{13}$. The diagnosis of T2D was made using the American Diabetes Association criteria ${ }^{14}$.

GFR was estimated by the CKD-Epidemiology Collaboration formula; it was stratified as high (GFR > $130 / 120 \mathrm{~mL} / \mathrm{min} / 1.73 \mathrm{~m}^{2} \mathrm{M} / \mathrm{W}$ ), normal (GFR $\geq$ 90-120 and $\left.90-130 \mathrm{~mL} / \mathrm{min} / 1.73 \mathrm{~m}^{2} \mathrm{~W} / \mathrm{M}\right)$, and low GFR $\left(<90 \mathrm{~mL} / \mathrm{min} / 1.73 \mathrm{~m}^{2}\right)$. Proteinuria was evaluated with protein reactive strips (ROCHE, Urisys 2400). The presence of $\geq 15-500 \mathrm{mg} / \mathrm{dL}$ of protein, without the presence of bacteria, nitrites, hemoglobin, or erythrocytes in the urinalysis was considered positive proteinuria ${ }^{15}$.

\section{Statistical analysis and ethical considerations}

Student's t-test and z-test were used to assess statistical significance for datasets with continuous variables and proportions, respectively. Logistic regression was performed for OR computation and 95\% confidence intervals $(\mathrm{Cl})$, adjusted by sex. Differences between groups were considered statistically significant if $p<0.05$ was reached, and if we could compute of population attributable risk (PAR).

A log-linear model was used to compute the probability of adding the specific risk factors (HBP, UA, HDLC, and LDL-C) to obesity combined with any kidney disorder (e.g., low GFR, high GFR, or proteinuria). The log-linear model was adjusted with 2-way and 3-way interactions. Coefficients that reached $p<0.10$ were maintained in the model. The loadings of main effects were used for the estimation of frequencies, odds, and probability. The estimated frequencies were calculated with:

$$
\text { freq }=e^{\alpha+\sum \lambda \chi}
$$

In this equation, $\lambda$ is the loading for each variable or interaction and $\alpha$ is the linear intercept; both parameters were used as exponential link for generalized lineal modeling. In these probabilistic models, we considered a variable as clinically significant if it had $p$ > 0.50 . All statistical analyses were performed with packages SPSS v.22 and Epidat 3.0.

The study was designed following the Helsinki Declaration and was reviewed and approved by the
Committee of Ethics and Institutional Research, registry key DI/16/105-B/04/056. Statistical analysis of the data was carried out during the period of 2017-2018.

\section{RESULTS}

\section{Anthropometry, clinical variables, and CMRFs}

Anthropometry, clinical characteristics, and the prevalence of risk factors of the sampled subjects are shown in table $1 a$ and $b$. No CKD risk factor was found in $22 \%$ of the subjects $(n=1219)$. In contrast, $49 \%$ of the subjects $(n=2691)$ had two or more CMRFs for CKD. Women had a higher frequency of two or more risk factors when compared to men ( $25 \%$ vs. $17 \%, p<0.001$ ).

Only $1 \%$ of the students $(n=59)$ had hypertension (BP $\geq 140 / 90 \mathrm{mmHg}$ ) and eight subjects had T2D. HOMA-IR was measured in a subsample of 2884 subjects ( $68 \%[n=1959]$ were women). The mean serum concentrations of insulin in women were $10.8 \pm 8.7 \mathrm{IU}$ and in men were $8.7 \pm 5.2 \mathrm{IU}(\mathrm{p}<0.001)$. IR was found in $25 \%(n=723)$ of the subjects (Table 1$)$.

\section{Renal function}

Renal function stratified by sex and presence of proteinuria is presented in table 2 . Proteinuria was found in $3 \%(n=170)$ of individuals and was more frequent in males ( $4 \%$ vs. $3 \%, p=0.02$ ). High GFR (hyperfiltration) was found in $33 \%(n=1830)$ of the subjects and was more common in females ( $43 \%$ vs. $8 \%$, $p<0.01$ ). Low GFR was identified in $3 \%$ of the subjects $(n=161)$.

\section{CMRFs and renal function}

The CMRFs associated with low GFR were UA (OR = $1.8)$, hypercholesterolemia $(O R=1.66)$, and proteinuria $(O R=3.4)$ and those associated with high GFR were $h B M l(O R=1.3)$, hyperuricemia $(O R=0.2)$, and $\mathrm{HDL}$ risk $(\mathrm{OR}=1.4)$. Proteinuria was associated with hyperuricemia $(O R=1.59)$ and with hypercholesterolemia $(O R=1.8)$. Table $1 S$ shows additional details of the relation between CMRFs and renal function. 
Table 1a. Anthropometry and clinical data of population, by sex

\begin{tabular}{|c|c|c|c|c|}
\hline & $\begin{array}{c}\text { Total } \\
\mathrm{n}=5531 \\
(\%)\end{array}$ & $\begin{array}{c}\text { Men } \\
\mathrm{n}=1781 \\
(32 \%)\end{array}$ & $\begin{array}{c}\text { Women } \\
n=3750 \\
(68 \%)\end{array}$ & $\mathrm{p}$ \\
\hline Age $(x \pm S D)$ & $19.31 \pm 1.6$ & $20 \pm 2$ & $19 \pm 2$ & $<0.001$ \\
\hline $\mathrm{BMI} \mathrm{kg} / \mathrm{m}^{2}(\mathrm{x} \pm \mathrm{SD})$ & $24.12 \pm 4.27$ & $24.41 \pm 4.38$ & $23.99 \pm 4.22$ & $<0.001$ \\
\hline Underweight (\%) & $267(5)$ & $77(4)$ & $190(5)$ & 0.25 \\
\hline Appropriate weight & $3322(61)$ & $1041(59)$ & $2281(62)$ & 0.09 \\
\hline Overweight & $1331(24)$ & $438(25)$ & $893(24)$ & 0.54 \\
\hline Obesity I & $437(8)$ & $173(10)$ & $264(7)$ & $<0.001$ \\
\hline Obesity II & $93(2)$ & $30(2)$ & $63(2)$ & 0.92 \\
\hline Obesity III & $19(1)$ & $7(0.4)$ & $12(0.3)$ & 0.85 \\
\hline WC $(\mathrm{cm})$ & $81.9 \pm 11.21$ & $84.44 \pm 11.65$ & $80.71 \pm 10.79$ & $<0.001$ \\
\hline $\mathrm{DBP}(\mathrm{mmHg})$ & $73 \pm 9$ & $77 \pm 9$ & $71 \pm 9$ & $<0.001$ \\
\hline SBP $(m m H g)$ & $108 \pm 12$ & $114 \pm 12$ & $105 \pm 11$ & $<0.001$ \\
\hline Central obesity (WC) & 2164 (39) & $449(25)$ & $1715(46)$ & $<0.001$ \\
\hline $\mathrm{Ow} / \mathrm{OB}(\mathrm{BMI})$ & $1880(34)$ & $648(37)$ & $1232(33)$ & 0.01 \\
\hline $\mathrm{UA}>6.8 \mathrm{mg} / \mathrm{dL}$ & $688(12)$ & $584(33)$ & $104(3)$ & $<0.001$ \\
\hline Triglycerides $\geq 150 \mathrm{mg} / \mathrm{dL}$ & $956(17)$ & $389(22)$ & $567(15)$ & $<0.001$ \\
\hline Cholesterol $\geq 200 \mathrm{mg} / \mathrm{dL}$ & $639(12)$ & $199(11)$ & $440(12)$ & 0.57 \\
\hline HDL-C risk & $2568(46)$ & $509(29)$ & $2059(55)$ & $<0.001$ \\
\hline $\mathrm{LDL}-\mathrm{C}>130 \mathrm{mg} / \mathrm{dL}$ & $437(8)$ & $147(8)$ & $290(8)$ & 0.53 \\
\hline Glucose $\geq 100 \mathrm{mg} / \mathrm{dL}$ & $428(8)$ & $203(11)$ & $225(6)$ & $<0.001$ \\
\hline $\mathrm{SBP} \geq 130 \mathrm{mmHg}$ & $321(6)$ & $221(13)$ & $100(3)$ & $<0.001$ \\
\hline $\mathrm{DBP} \geq 85 \mathrm{mmHg}$ & $412(8)$ & $237(13)$ & $175(5)$ & $<0.001$ \\
\hline Proteinuriaa & $170(3)$ & $69(4)$ & $101(3)$ & 0.03 \\
\hline Metabolic syndrome & $732(13)$ & $264(15)$ & $468(13)$ & 0.01 \\
\hline HOMA-IR* & $723(25)$ & $266(37)$ & $457(63)$ & 0.002 \\
\hline
\end{tabular}

Results of continuous variables presented as mean \pm standard deviation; categorical variables, as proportions.

*HOMA-IR: subsample of 2884 subjects. $n=5430$; Men: 1775 ; Women: 3655 ; Central obesity: WC $\geq 90 \mathrm{~cm}$ in men, $\geq 80 \mathrm{~cm}$ for women. DBP, diastolic blood pressure; SBP, systolic blood pressure; Ow, overweight; OB, obesity; UA, uric acid; HDL-C risk: < 50 mg/dl for women/ $40 \mathrm{mg} / \mathrm{dl}$ in men.

WC, waist circumference.

\section{IR and renal function}

Table 3 shows the estimations of crude and adjusted OR by sex for IR and impaired renal function. IR was significantly associated with high GFR $(O R=1.3)$, whereas the PAR for proteinuria was $14 \%$.

Figure 1 shows the probability (using a log-linear model) of having low/high GFR or proteinuria in the presence of obesity and other CMRFs when compared to obesity alone. The threshold of clinical relevance was defined as $p>0.2$ (20\%) when compared to obesity alone. The presence of obesity with low
$\mathrm{HDL}-\mathrm{C}$, high UA, or their combination increases the likelihood of having low GFR and proteinuria. Meanwhile, hyperfiltration probability was slightly increased with obesity and low HDL-C, but not with UA.

\section{DISCUSSION}

The present study shows that $76 \%$ of our study population comprising $1^{\text {st }}$ year university students had at least one CMRF associated with a future CKD risk. This young population is considered healthy, and due to this misconception, they are not either screened 
Table 1b. Biochemical parameters, by sex (continued)

\begin{tabular}{|c|c|c|c|c|}
\hline & $\begin{array}{c}\text { Total } \\
\mathrm{n}=5531 \\
(100 \%)\end{array}$ & $\begin{array}{c}\text { Men } \\
\mathrm{n}=1781 \\
(32 \%)\end{array}$ & $\begin{array}{c}\text { Women } \\
\mathrm{n}=3750 \\
(68 \%)\end{array}$ & $\mathrm{p}$ \\
\hline Hemoglobin (g/dL) & $15.36 \pm 1.41$ & $16.9 \pm 0.9$ & $14.6 \pm 1$ & $<0.001$ \\
\hline Total leukocytes $10^{3} / \mu \mathrm{L}$ & $7.19 \pm 1.71$ & $6.65 \pm 1.56$ & $7.46 \pm 1.73$ & $<0.001$ \\
\hline Platelets $10^{3} / \mu \mathrm{L}$ & $298 \pm 62.7$ & $274 \pm 58$ & $310 \pm 62$ & $<0.001$ \\
\hline Albumin (mg/dL) & $4.5 \pm 0.29$ & $4.6 \pm 0.3$ & $4.4 \pm 0.3$ & $<0.001$ \\
\hline Urea $^{\circ}(\mathrm{mg} / \mathrm{dL})$ & $24.7 \pm 6.65$ & $27.8 \pm 6.5$ & $23.2 \pm 6.2$ & $<0.001$ \\
\hline Creatinine $(\mathrm{mg} / \mathrm{dL})$ & $0.81 \pm 0.15$ & $0.95 \pm 0.12$ & $0.76 \pm 0.13$ & $<0.001$ \\
\hline Triglycerides (mg/dL) & $112 \pm 66$ & $121 \pm 89$ & $108 \pm 51$ & $<0.001$ \\
\hline Total cholesterol (mg/dL) & $166 \pm 30$ & $165 \pm 30$ & $166 \pm 30$ & 0.24 \\
\hline LDL-C (mg/dL) & $95.2 \pm 24.6$ & $96 \pm 25$ & $95 \pm 25$ & 0.16 \\
\hline $\mathrm{HDL}-\mathrm{C}(\mathrm{mg} / \mathrm{dL})$ & $47.9 \pm 9.8$ & $45 \pm 9$ & $49 \pm 10$ & $<0.001$ \\
\hline Glucose (mg/dL) & $89.1 \pm 9.4$ & $91 \pm 11$ & $88 \pm 8$ & $<0.001$ \\
\hline UA $(m g / d L)$ & $5.1 \pm 1.37$ & $6.28 \pm 1.24$ & $4.55 \pm 1.05$ & $<0.001$ \\
\hline eGFR $\mathrm{mL} / \mathrm{min} / 1.73 \mathrm{~m}^{2}$ & $114.6 \pm 12.81$ & $115 \pm 13$ & $114 \pm 13$ & 0.007 \\
\hline Insulin IU* & $10.15 \pm 6.25$ & $8.72 \pm 5.28$ & $10.8 \pm 6.56$ & $<0.001$ \\
\hline
\end{tabular}

*Subsample of 2884 subjects. Results of continuous variables presented as mean \pm standard deviation. WC, waist circumference; c, cholesterol; UA, uric acid; eGFR, estimated glomerular filtration rate. ${ }^{\circ} \mathrm{n}=1693$ (men 564, women 1129).

Table 2. Renal function and proteinuria

\begin{tabular}{|c|c|c|c|c|c|c|}
\hline \multirow[t]{3}{*}{ eGFR mL/min/1.73 $\mathrm{m}^{2}$} & \multicolumn{5}{|l|}{ Proteinuria } & \multirow[t]{3}{*}{$\mathrm{p}^{* *}$} \\
\hline & \multirow[b]{2}{*}{$\begin{aligned} \text { Total } & \\
\mathrm{n}= & 5430(\%)\end{aligned}$} & \multicolumn{2}{|c|}{$\begin{array}{c}\text { Women } \\
n=3655(67 \%)\end{array}$} & \multicolumn{2}{|c|}{$\begin{array}{c}\text { Men } \\
n=1775(33 \%)\end{array}$} & \\
\hline & & $\begin{array}{c}\text { With } \\
\text { proteinuria } \\
n=101(3 \%)\end{array}$ & $\begin{array}{c}\text { Without } \\
\text { proteinuria } \\
\mathrm{n}=3554(97 \%)\end{array}$ & $\begin{array}{c}\text { With } \\
\text { proteinuria } \\
n=69(4 \%)\end{array}$ & $\begin{array}{c}\text { Without } \\
\text { proteinuria } \\
\mathrm{n}=1706(96 \%)\end{array}$ & \\
\hline$<15$ & 1 & $1(0.27)$ & - & - & - & - \\
\hline $15-29$ & - & 0 & - & - & - & - \\
\hline $30-59$ & 3 & $1(0.27)$ & - & $1(0.027)$ & 1 & - \\
\hline $60-89$ & $157(3)$ & $9(0.25)$ & $83(2.2)$ & $8(0.45)$ & $57(3.2)$ & 0.31 \\
\hline$\geq 90$ & $3494(64)$ & $57(1.5)$ & $1882(51.4)$ & $57(3.2)$ & $1498(84.4)$ & $<0.01$ \\
\hline$>130 \mathrm{M},>120 \mathrm{~W}^{*}$ & $1775(33)$ & $33(0.9)$ & $1589(43.4)$ & $3(0.16)$ & $150(8.4)$ & $<0.01$ \\
\hline
\end{tabular}

*Adjusted by sex M: men and W: women. Results of categorical variables presented as proportions.

**Value of p, obtained when comparing the frequency of proteinuria by sex. eGFR, estimated glomerular filtration rate; CKD, chronic kidney disease.

for any risk factor or are any interventions implemented in them to modify risk factors ${ }^{9,16}$. Obesity, when combined with other $\mathrm{CMRF}^{9,17,18}$, can lead to progressive decrease in GFR. Such a decrease can start 30 years before CKD diagnosis in adulthood $^{9,18-24}$. Adolescents in Mexico have a $36 \%$ prevalence of overweight and obesity, and during early adulthood (20-29 years), the prevalence increases to as much as $72 \%{ }^{25}$.

BP levels, although still in the normal range, were closer to the upper threshold (130-139/85-89 $\mathrm{mmHg})$, and this may double the risk of hypertension and cardiovascular disease (CVD) and could increase CKD risk 
Figure 1. Log-linear model of the probability of having low or high glomerular filtration rate or proteinuria in the presence of obesity and other CMRFs when compared to obesity alone. HBP: high blood pressure; LDL: low-density lipoprotein; HDL: highdensity lipoprotein; UA: uric acid; CMRFs: cardiometabolic risk factors.

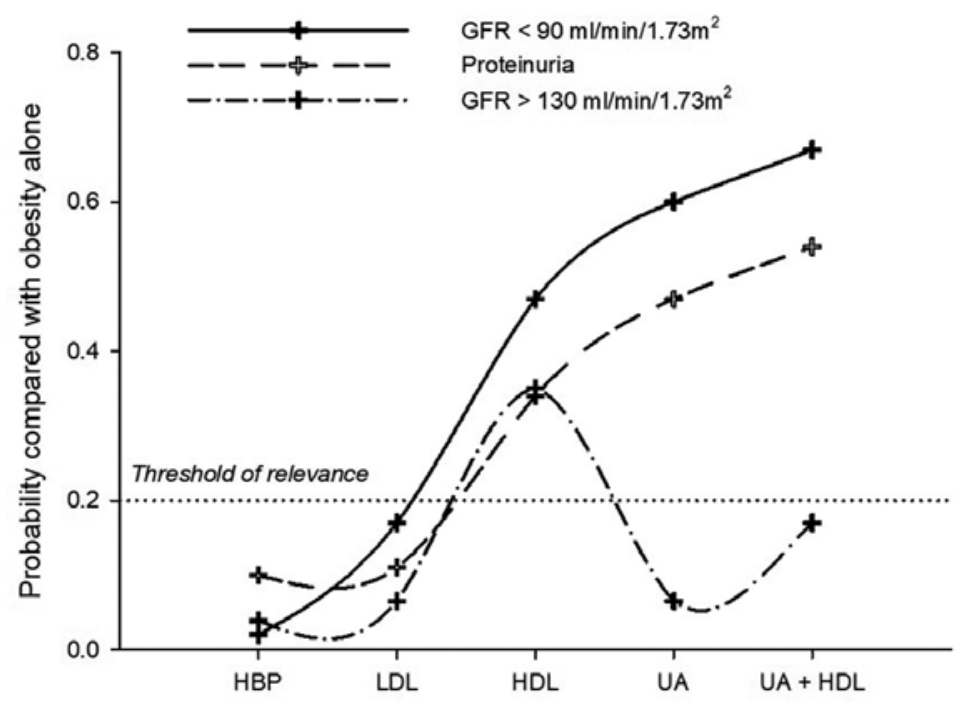

in the future $26-28$. In our population, $13 \%$ of the students had marginally elevated BP levels, and only $1 \%$ showed hypertension. Regarding dyslipidemias, our sample showed a high prevalence of low serum HDL-C (46\%) followed by hypertriglyceridemia (17\%) and hypercholesterolemia (11.5\%). All of them are associated with CKD development ${ }^{16,29-31}$ and could be detected 30 years before CKD diagnosis ${ }^{9,31}$.

Elevated level of UA is an asymptomatic CMRF found in $12 \%$ of our young population. It is known that the development of CKD is related to the duration of exposure to elevated levels of UA. The proposed mechanisms are endothelial dysfunction; glomerular hypertrophy; proliferation of vascular smooth muscle cells, secondary to the activation of cyclooxygenase- 2 plus MCP-1; and the activation of the reninangiotensin system ${ }^{32-36}$. Interestingly, our log-linear model suggested the combination of obesity and hyperuricemia, which gave $p=0.6$ of low GFR when adding low HDL-C increased it to 0.66. Early intervention in this age group could help to reduce the impact of this risk factor in the long term.

The presence of $\mathrm{MetS}^{36}$ portends increased risk to CKD development after 20 years ${ }^{6,37}$. Our cross-sectional findings suggest that the sum of CMRFs does not confer a greater risk, but the presence of each component separately and a combination of specific
CMRFs might have a better predictive value. This finding supports the need to tailor the current MetS criteria based on the specific population under study for accurate model development to predict CKD in the young population.

We found low prevalence $(<1 \% ; n=4)$ of GFR $<60$ $\mathrm{mL} / \mathrm{min} / 1.73 \mathrm{~m}^{2}$ in students, compared with students in Thailand, where the prevalence of CKD was $6.8 \%$. We found that $3 \%$ of our subjects had low GFR, which is similar to the prevalence reported by Hill et al. ${ }^{6}$

In the previous studies, high GFR was not evaluated as an incipient marker of impaired renal function, but some studies reported an association with cardiovascular morbidity and mortality ${ }^{38}$. We found that 33\% of young people with this condition were associated with IR (OR 1.3), HDL-C of risk (OR 1.4), and hBMI (OR 1.3). We also found that UA concentrations $<6.8 \mathrm{mg} / \mathrm{dL}$ were inversely correlated with GFR (OR $0.2,95 \% \mathrm{Cl}: 0.15,0.26, \mathrm{p}<0.001$ ), in accordance with the previous studies ${ }^{34}$. Our log-linear analysis supports a model where a combination of two or more CMRFs is associated with high GFR with $\mathrm{p}>0.4$.

A limitation of our study is the lack of a second measurement of proteinuria, as currently recommended. In our population, after excluding participants with 
Table 3. Insulin resistance associated to renal function*

\begin{tabular}{lccccccc}
\hline & OR & $95 \% \mathrm{Cl}$ & $\mathrm{p}$ & ORa* & $95 \% \mathrm{Cl}$ & $\mathrm{p}$ & PAR (\%) \\
\hline CKD-EPI $<90 \mathrm{~mL} / \mathrm{min} / 1.73 \mathrm{~m}^{2}$ & 0.76 & $0.47-1.2$ & 0.26 & 0.77 & $0.48-1.2$ & 0.29 & 6.07 \\
eGFR $>130 \mathrm{~mL} / \mathrm{min} / 1.73 \mathrm{~m}^{2}$ & 1.09 & $0.90-1.3$ & 0.35 & 1.3 & $1.05-1.7$ & 0.01 & 5.9 \\
Proteinuria & 1.8 & $0.99-3.3$ & 0.52 & 1.81 & $0.98-3.3$ & 0.057 & 14 \\
\hline
\end{tabular}

*Analysis performed in subsample of 2785 subjects ( $I R=25 \%$ ). Data presented as odds ratio ( $95 \%$ confidence interval).

**OR adjusted by sex. eGFR, estimated glomerular filtration rate; CKD, chronic kidney disease; PAR, population attributable risk.

suspected menstruation period, urinary infections or suspected secondary causes for the presence of urinary protein, the prevalence of proteinuria was $3 \%$, which is in agreement with reports from other authors ${ }^{35,39,41}$. The presence of proteinuria has been previously associated with hypercholesteremia ${ }^{18,42}$ and high levels of UA (OR 1.59). The use of dipstick is common in epidemiological research. A metaanalysis examined potential sources of heterogeneity among studies and found no difference between the strips compared with laboratory measurement (RR $1.4,95 \% \mathrm{Cl} 1.2,1.7$ vs. $1.7,95 \% \mathrm{Cl} 1.2,2.5$; $\mathrm{p}=0.5)^{43}$. However, the same group reported that the dipsticks have slightly lower sensitivity for the prediction of stroke whn compared to laboratory measurement ${ }^{44}$.

Interestingly, $30 \%$ of the students with renal function abnormalities did not have any of the examined risk factors, which suggests that factors not assessed during this study may be potentially involved in possible CKD development. These may include dietary habits, inheritance/family history, tobacco/alcohol consumption, and interaction of genes with environmental factors.

Reproducibility of proteinuria prevalence is hard to define. A study in young population (although older than our sample) found a prevalence of proteinuria of $2.5 \%$ in male and $1.7 \%$ in female subjects, using dipstick for urine ${ }^{45}$. Research conducted in Mexico in adult population ${ }^{46}$ found $14 \%$ prevalence of microalbuminuria; however, this study did not include young subjects. Since we could not verify the validity of our results in an independent cohort, we have ongoing studies in three Mexican universities, two of them in Reynosa, Tamaulipas (Universidad Mexico-Americana del Norte and Universidad Autónoma de Tamaulipas) and one more in Monterrey (Universidad Autónoma de Nuevo León), which will allow us to confirm our results in additional cohorts.
There is a high prevalence of CMRFs in otherwise "apparently" healthy Mexican young adults and adolescents. The coexistence of some of these risk factors such as hyperuricemia, hBMI, and HDL-C predicts altered renal function which increases the risk of development and progression of CKD and CVD ${ }^{21-23}$. Based on our findings, it is appropriate to consider the implementation of public health measures focused on the detection and timely treatment in this age group, which could have a positive health impact by decreasing the risk of development and progression of CKD and CVD in adulthood.

In conclusion, our findings revealed that young individuals have unexpected high prevalence (about 30\%) of abnormal findings in renal function, and more than $70 \%$ had at least one CMRFs. Among CMRFs, hyperuricemia, hBMl, and $\mathrm{HDL}-\mathrm{c}$ of risk predict alterations in renal function. Finally, there is a need for public health programs focused on the detection and timely treatment in this age group to impact on the development and progression of renal diseases.

\section{SUPPLEMENTARY DATA}

Supplementary data are available at Revista de Investigación Clínica online (www.clinicalandtranslationalinvestigation.com). These data are provided by the corresponding author and published online for the benefit of the reader. The contents of supplementary data are the sole responsibility of the authors.

\section{REFERENCES}

1. GBD 2016 Causes of Death Collaborators. Global, regional, and national age-sex specific mortality for 264 causes of death, 1980-2016: a systematic analysis for the global burden of disease study 2016. Lancet. 2017;390:1151-210.

2. Saran R, Robinson B, Abbott KC, Agodoa LYC, Bhave N, BraggGresham J, et al. US renal data system 2017 annual data report: epidemiology of kidney disease in the United States. Am J Kidney Dis. 2018;71:A7. 
3. Garcia-Garcia G, Monteon-Ramos JF, Garcia-Bejarano H, Gomez-Navarro B, Reyes IH, Lomeli AM, et al. Renal replacement therapy among disadvantaged populations in Mexico: a report from the Jalisco dialysis and transplant registry (REDTJAL). Kidney Int Suppl. 2005;97:S58-61.

4. Tsai WC, Wu HY, Peng YS, Ko MJ, Wu MS, Hung KY, et al. Risk factors for development and progression of chronic kidney disease: a systematic review and exploratory meta-analysis. Medicine (Baltimore). 2016;95:e3013.

5. Thomas G, Sehgal AR, Kashyap SR, Srinivas TR, Kirwan JP, Navaneethan SD. Metabolic syndrome and kidney disease: a systematic review and meta-analysis. Clin J Am Soc Nephrol. 2011;6:2364-73

6. Hill NR, Fatoba ST, Oke JL, Hirst JA, O'Callaghan CA, Lasserson DS, et al. Global prevalence of chronic kidney disease a systematic review and meta-analysis. PLoS One. 2016;11:e0158765

7. Alegría-Díaz A, Valdez-Ortiz R, Murguía-Romero M, JiménezFlores R, Villalobos-Molina R, Mummidi S, et al. Clinical significance of serum uric acid levels in Mexican young adults. Contrib Nephrol. 2018;192:125-34.

8. Liceaga E. Secretaría de Salud. Hospital General de México 2018. Available from: http://www.hgm.salud.gob.mx/descargas/pdf/ dirgral/programa_2015.pdf. Last accessed: November 10, 2019.

9. McMahon GM, Preis SR, Hwang SJ, Fox CS. Mid-adulthood risk factor profiles for CKD. L An Soc Nephrol. 2014:25:2633-41.

10. Tozawa M, Iseki K, Iseki C, Kinjo K, Ikemiya Y, Takishita S. Blood pressure predicts risk of developing end-stage renal disease in men and women. Hypertension. 2003:41:1341-5.

11. Murguía-Romero M, Jiménez-Flores JR, Sigrist-Flores SC, TapiaPancardo DC, Jiménez-Ramos A, Méndez-Cruz AR, et al. Prevalence of metabolic syndrome in young Mexicans: a sensitivity analysis on its components. Nutr Hosp. 2015:32:189-95.

12. Consejo de Salubridad General. Guía de Práctica Clínica Prevención, Diagnóstico, Tratamiento y Referencia Oportuna de Hiperuricemia y Gota, México 2011. Available from: http://www. cenetec.salud.gob.mx/descargas/gpc/CatalogoMaestro/216 SSA_09_Hiperuricemia_Gota/GRR_SSA_216_09.pdf. Last accessed: Ōctober 20, 2019.

13. Alberti KG, Eckel RH, Grundy SM, Zimmet PZ, Cleeman JI, Donato KA, et al. Harmonizing the metabolic syndrome: a joint interim statement of the international diabetes federation task force on epidemiology and prevention; national heart, lung, and blood institute; American heart association; world heart federation; international atherosclerosis society; and international association for the study of obesity. Circulation. 2009:120:1640-5.

14. American Diabetes Association. 2. Classification and diagnosis of diabetes: standards of medical care in diabetes-2019. Diabetes Care. 2019;42:S13-S28.

15. Inker LA Astor BC, Fox CH, Isakova $T$, Lash JP Peralta CA et al. KDOQI US commentary on the $2012 \mathrm{KDIGO}$ clinical practice guideline for the evaluation and management of CKD. Am J Kidney Dis. 2014;63:713-35.

16. Pscheidt C, Nagel G, Zitt E, Kramar R, Concin H, Lhotta K. Sex and time-dependent patterns in risk factors of end-stage renal disease: a large Austrian cohort with up to 20 years of followup. PLoS One. 2015;10:e0135052.

17. Gelber RP, Kurth T, Kausz AT, Manson JE, Buring JE, Levey AS, et al. Association between body mass index and CKD in apparently healthy men. Am J Kidney Dis. 2005;46:871-80.

18. Chronic Kidney Disease Prognosis Consortium, Matsushita K, van der Velde M, Astor BC, Woodward M, Levey AS, et al. Association of estimated glomerular filtration rate and albuminuria with allcause and cardiovascular mortality in general population cohorts: a collaborative meta-analysis. Lancet. 2010;375:2073-81.

19. Kramer H, Luke A, Bidani A, Cao G, Cooper R, McGee D. Obesity and prevalent and incident CKD: the hypertension detection and follow-up program. Am J Kidney Dis. 2005:46:587-94.

20. Ejerblad E, Fored CM, Lindblad P, Fryzek J, McLaughlin JK, Nyrén O. Obesity and risk for chronic renal failure. J Am Soc Nephrol. 2006:17:1695-702.

21. Silverwood RJ, Pierce M, Hardy R, Thomas C, Ferro C, Savage C, et al. Early-life overweight trajectory and CKD in the 1946 British birth cohort study. Am J Kidney Dis. 2013;62:276-84

22. Grubbs V, Lin F, Vittinghoff E, Shlipak MG, Peralta CA, Bansal N, et al. Body mass index and early kidney function decline in young adults: a longitudinal analysis of the CARDIA (coronary artery risk development in young adults) study. Am J Kidney Dis. 2014;63:590-7.

23. Vivante A, Golan E, Tzur D, Leiba A, Tirosh A, Skorecki K, et al. Body mass index in 1.2 million adolescents and risk for endstage renal disease. Arch Intern Med. 2012;172:1644-50.
24. Wang Y, Chen X, Song Y, Caballero B, Cheskin LJ. Association between obesity and kidney disease: a systematic review and meta-analysis. Kidney Int. 2008;73:19-33.

25. Hernández M Rivera J, Shamah T Cuevas L, Gaona E, Romero M. Informe Final de Resultados Proyecto CIPMA-FMAM. Vol. 2016. Mexico: Reporte de Resultados ENSANUT MC; 2016.

26. Huang Y, Cai X, Zhang J, Mai W, Wang S, Hu Y, et al. Prehypertension and Incidence of ESRD: a systematic review and metaanalysis. Am J Kidney Dis. 2014;63:76-83.

27. Sundin PO, Udumyan R, Sjöström P, Montgomery S. Predictors in adolescence of ESRD in middle-aged men. Am J Kidney Dis. 2014;64:723-9.

28. Elliot WJ, Black HR. Prehypertension. Nat Clin Pract Cardiovasc Med. 2007:4:538-48.

29. Noborisaka Y, Ishizaki M, Yamada Y, Honda R, Yokoyama H, Miyao $M$, et al. Distribution of and factors contributing to chronic kidney disease in a middle-aged working population. Environ Health Prev Med. 2013:18:466-76.

30. Schaeffner ES, Kurth T, Curhan GC, Glynn RJ, Rexrode KM, Baigent $C$, et al. Cholesterol and the risk of renal dysfunction in apparently healthy men. J Am Soc Nephrol. 2003;14: 2084-91.

31. Rahman M, Yang W, Akkina S, Alper A, Anderson AH, Appel LJ, et al. Relation of serum lipids and lipoproteins with progression of CKD. the CRIC study Clin J Am Soc Nephrol. 2014:9:1190-8.

32. Li L, Yang C, Zhao Y, Zeng X, Liu F, Fu P. Is hyperuricemia an independent risk factor for new-onset chronic kidney disease? A systematic review and meta-analysis based on observational cohort studies. BMC Nephrol. 2014:15:122.

33. Mende C. Management of chronic kidney disease: the relationship between serum uric acid and development of nephropathy. Adv Ther. 2015;32:1177-91.

34. Mok Y, Lee SJ, Kim MS, Cui W, Moon YM, Jee SH. Serum uric acid and chronic kidney disease: the severance cohort study. Nephrol Dial Transplant. 2012;27:1831-5.

35. Nguyen S, McCulloch C, Brakeman P, Portale A, Hsu CY. Being overweight modifies the association between cardiovascular risk factors and microalbuminuria in adolescents. Pediatrics. 2008:121:37-45

36. Nagel G, Zitt E, Peter R, Pompella A, Concin H, Lhotta K. Body mass index and metabolic factors predict glomerular filtration rate and albuminuria over 20 years in a high-risk population. BMC Nephrol. 2013;14:177.

37. Jang SY, Kim IH, Ju EY, Ahn SJ, Kim DK, Lee SW. Chronic kidney disease and metabolic syndrome in a general Korean population: the third Korea national health and nutrition examination survey (KNHANES III) study. J Public Health (Oxf). 2010;32:538-46.

38. Choi HM, Hyun YY, Lee KB, Kim H. High estimated glomerular filtration rate is associated with coronary artery calcification in middle-aged Korean men without chronic kidney disease. Nephrol Dial Transplant. 2015;30:996-1001.

39. Seo WJ, Lee GM, Hwang JH, Lee MN, Kang HC. Association between body mass index, waist circumference and prevalence of microalbuminuria in Korean adults of age 30 years and older without diabetes, hypertension, renal failure, or overt proteinuria: the 2013 Korean national health and nutrition examination survey. Korean J Fam Med. 2016;37:57-63.

40. Gurecká R, Koborová I, Šebek J, Šebeková K. Presence of cardiometabolic risk factors is not associated with microalbuminuria in 14-to-20-years old slovak adolescents: a cross-sectional, population study. PLoS One. 2015;10:e0129311.

41. $\mathrm{Cho} \mathrm{H}, \mathrm{Kim} \mathrm{JH}$. Prevalence of microalbuminuria and its associated cardiometabolic risk factors in Korean youth: data from the Korea national health and nutrition examination survey. PLoS One. 2017;12:e0178716.

42. Lee HO, Bak HJ, Shin JY, Song YM. Association between metabolic syndrome and microalbuminuria in Korean adults. Korean J Fam Med. 2015;36:60-71.

43. Perkovic V, Verdon C, Ninomiya T, Barzi F, Cass A, Patel A, et al. The relationship between proteinuria and coronary risk: a systematic review and meta-analysis. PLoS Med. 2008;5:e207

44. Ninomiya T, Perkovic V, Verdon C, Barzi F, Cass A, Gallagher M, et al. Proteinuria and stroke: a meta-analysis of cohort studies. Am J Kidney Dis. 2009:53:417-25.

45. You DY, Wu ZY, Wan JX, Cui J, Zou ZH. Analysis of renal functions and proteinuria in young obese adults. J Endocrinol Invest. 2015;38:901-8.

46. Corona AJ, Martinez DR, Avila MH, Haffner S, Williams K, González Villalpando ME, et al. Microalbuminuria as a predictor of myocardial infarction in a Mexican population: the Mexico city diabetes study. Kidney Int Suppl. 2005;97:S34-9. 